\title{
Economics
}

\section{About the Profits of an Entrepreneur in the Cost Approach}

\section{Sergey Viktorovich Gribovsky}

Higher School of Economics, St. Petersburg State University of Economics, St. Petersburg, Russia

\section{Email address:}

S.Gribovsky@ko.spb.ru

\section{To cite this article:}

Sergey Viktorovich Gribovsky. About the Profits of an Entrepreneur in the Cost Approach. Economics. Vol. 8, No. 2, 2019 , pp. 49-54. doi: $10.11648 /$ j.eco.20190802.12

Received: March 18, 2019; Accepted: April 22, 2019; Published: May 15, 2019

\begin{abstract}
The article is devoted to one of the debatable problems of the theory and practice of valuation - the calculating of the profit of an entrepreneur in the cost approach to real estate valuation. Discusses the interpretation of the entrepreneur profit as a fair reward for the investor for the risk of investment in the creation of the property and its relationship with the entrepreneur incentive that is the driving force of the development process. The shortcomings inherent in the cost approach are analyzed: the assumption of the instant creation of land improvements and the impossibility of taking into account the risks of investing in the process of calculating their value. The proposed formula for calculating the profit of the entrepreneur for objects with different levels of risk, amount of funding and construction time, allowing to level these shortcomings.
\end{abstract}

Keywords: Real Estate, Land, Improvements, Costs, Capital, Valuation, Entrepreneur, Developer, Profit, Incentive, Cost Approach, Cash Flow, Discounting, Imputed Costs, Unrecovered Investments

\section{Introduction}

What is an entrepreneurial profit? How to define it? Is it always necessary to take into account?

Many practicing appraisers very often ask these and other questions related to the entrepreneurial profit (abbreviated EP) in the cost approach to the valuation of the property. Despite the rather large number of publications, devoted to this topic [1-8], the entrepreneurial profit remains one of the controversial issues of Russian and international valuation practice today.

In the general economic sense, profit is only a positive difference between total income and the costs of production or acquisition, storage, etc. However, the problem is the term is used mainly in the field of investment analysis or similar disciplines. The cost approach, as it is presented in our textbooks and standards $[6,7,13,15]$, is aloof from investment analysis, and "profit" is not a native concept for it. In the cost approach the profit of the entrepreneur we understand as a sum of money added to the costs for forming the value of improvements, which, together with the value of land, forms the value of selling the created real estate object.

The second problem that needs to be discussed is it is not clear whom this profit belongs to: an investor, a lender, an entrepreneur.
The third problem - what kind of profit should be calculated - is the profit on equity or on total capital, and how (by what methods) should it be calculated?

The appraisers are also interested in what to do in the period of a sharp fall in real estate prices: use the cost approach or not; if used, take profit or loss into account?

Perhaps these are the most important questions that we will try to answer in this article.

\section{Entrepreneur and His Profit}

In accordance with Article 2 of the Civil Code of the Russian Federation, a citizen's entrepreneurial activity is an independent, carried out at his own risk activity aimed at systematically receiving profit from using property, selling goods, performing work or providing services by persons registered in this capacity in accordance with the law. A person engaged in entrepreneurial activity we call an entrepreneur.

ABBYY Lingvo (Ru-En) ${ }^{1}$ provides a narrower definition of an entrepreneur: entrepreneur, businessperson - a person who creates, finances, and manages a commercial or industrial organization, expecting to make a profit.

In accordance with these definitions, an entrepreneur can

$1 \mathrm{http}: / /$ www.lingvo-online.ru/ru/search/en-ru 
be any person - from a major capitalist to a small shopkeeper. It all depends on the scale of the project. If a person leases a small space and arranges a shop there, then this is a small business owner. If, for example, a large plot of land is acquired, which does a large shopping or office center build up, this is already a large entrepreneur risking his capital in the interests of making profit at the exit from the project.

In this article, as an entrepreneur, we will most often mean a businessperson (investor2) who decides to start a small or large project, finances it himself at the expense of own or attracted funds, and participates in the management of this project. It should be noted that as an entrepreneur, it is possible to consider on the same conditions (to finance and make decisions) not one businessperson, but some of them in the structure of a joint stock company.

We note the failure of the very term "entrepreneur profit", which is used in the appraiser evaluation reports. As noted above, in the process of creating a property can participate not only its own, but also borrowed capital, and the term "entrepreneur's profit", as the name implies, means only return on equity. In this connection, it is more correct to understand the term "entrepreneur's profit" as the return on all invested capital that is attracted for the project, or, as proposed in [5], the profit of the development project.

The entrepreneur-developer provides financing and support of all stages of the creation of a real estate object from the acquisition of land to the registration of a finished real estate at its own expense or through its own, equity or/and borrowed funds. At the same time, for the development of a project, construction, and engineering support, an entrepreneur-developer engages on a contractual basis various contracting organizations. He manages the project of creating the property himself or hires a professional builder (general contractor, manager) for this, again on a contractual basis, paying, according to an agreed estimate, all the expenses of the latter and his profit. Financing all stages of creating a property, the entrepreneur expects to return the invested funds in full and make a profit adequate to the risks of such financing, or return on capital, invested in the creation of the property, when selling the property as a whole, in parts or renting it out. It is important that the base for the formation of the profit of the entrepreneur-developer in this case is the entire capital, both material or monetary (own or borrowed), and intellectual capital (his knowledge, experience).

\section{The Content and Economic Meaning of the Profit of the Entrepreneur}

In the well-known American edition [9, p. 23], it is noted that no reasonable developer will undertake to build and sell real estate without the possibility of not only returning initial investments, but also making a profit on capital. The

2An investor is any person who commits capital with the expectation of financial returns. Investors utilize investments in order to grow their money and/or provide an income during retirement, such as with an annuity. definition of the term under discussion is the next: entrepreneur is the difference between the total costs of creating a property and the market value of the created property. It is an incentive and compensation for the entrepreneur for the risk and his experience associated with a specific development project [9, p. 573].

From an economic point of view, the profit of an entrepreneur is a reasonable remuneration of an entrepreneur for the risk of investing in the creation of a property. This remuneration may manifest at the time of the sale of such an object in its entirety, in installments or upon lease. At the same time, the return of capital and profit (return on capital) is included in the sale or rental price.

A competent interpretation of the entrepreneur profit is given in the American edition [9]. It notes that the developer in the process of creating the property spends not only his money (capital) in the acquisition of land and the creation of improvements, but also invests his time and experience in the creation of the property. For this job, he expects to receive a fair reward - known as an entrepreneurial incentive, which is measured in the market by the entrepreneur profit. In other words, an entrepreneurial incentive is the predicted (expected) profit value that the investor is counting on, and an entrepreneurial profit is the amount of money that the investor will actually receive after the project is completed by selling the created real estate item. It can be said that the difference between incentive and profit is almost the same as the difference between value and price.

Note that in practice, at the end of a project, a developer, for various reasons, may receive not a profit, but a loss as a result, for example, of a sudden drop in demand for real estate. In the framework of the cost approach, we can qualify this situation as one of the types of wear. This loss cannot be predicted and incorporated into the model of valuation of the property. The appraiser, in the framework of the cost approach, does not calculate the profit of the entrepreneur, but only the estimation of this profit in the form of an entrepreneurial incentive, focusing on the most likely, in his opinion, scenario of using the property, which it determines in the process of analyzing its greatest and best use. In other words, entrepreneurial incentive is forecasted (calculated) entrepreneurial profit.

The value of any durable goods consists of the sum of the costs of its creation (first costs or initial costs) and profit. It can be assumed that this amount is maximum at the time of the creation of the goods. Further, over time, as it ages, the value will decrease. And finally, there will come a time when the value of the goods will be equal to zero. In this regard, we can choose a monotonically decreasing function consisting of two components, each of which equally decreases from a certain initial value to zero (see Figure 1) as a model for the change in the value of this commodity.

Commercial real estate, created by developers, is a durable product, and the dynamics of changes in the value of improvements to its land plot can be described by an analogous monotonous function. At the same time, at the initial moment of time this value will be the sum of the 
maximum values of first cost and profits (see Figure 1, time $\mathrm{t}_{0}$ ), and at some intermediate time point (see Figure 1, time $\mathrm{t}_{1}$ ) it will consist of the same components, but in reduced sizes.
These reduced first cost can be qualified as depreciated replacement costs, and reduced profit as amortized profits.

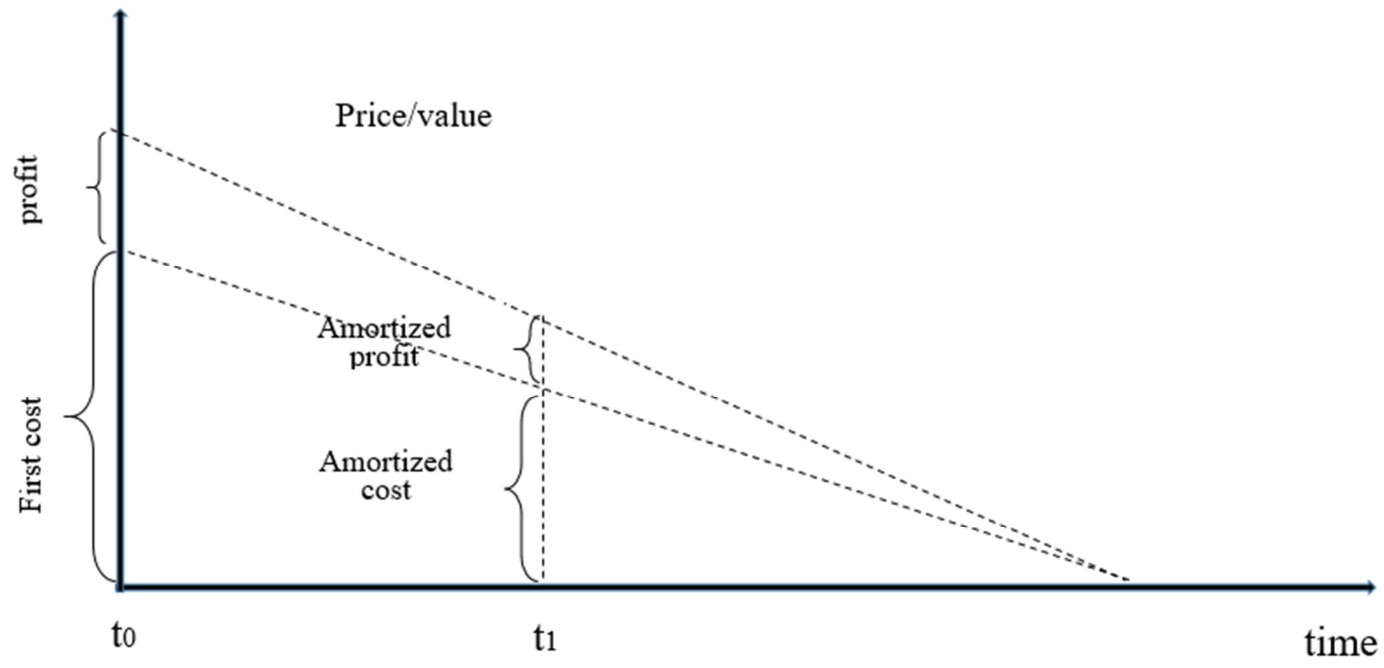

Figure 1. The dynamics of changes of land improvements value.

Example. A newly built property is being evaluated, consisting of a land plot and its improvements. By the date of evaluation in the area of real estate prices fell by 40 percent. It is required to determine the residual value of land improvements.

\section{Proposed solution}

Assume that the first cost of creating the improvements was $\mathrm{CU}^{3} 1,000,00$. Entrepreneurial incentives were estimated at 20 percent of first cost. The fall in prices appraiser qualified as external wear.

The calculation of the first cost of improvements:

First cost $=$ CU $1,000,000$

Entrepreneurial incentive $=1,000,000 \times 0.2=200,000(\mathrm{CU})$.

First improvements value:

$$
=1,000,000+200,000=1,200,000(\mathrm{CU}) .
$$

Calculation of residual value of improvements:

Amortized cost

$$
=1,000,000 \times(1-0.4)=600,000(\mathrm{CU}) .
$$

Amortized profit

$$
=200,000 \times(1-0.4)=120,000(\mathrm{CU}) .
$$

The residual value of improvements $=600,000+120,000$ $=720,000(\mathrm{CU})$.

\section{Result discussion}

Calculations showed that the residual value of almost new improvements due to depreciation was CU 280,000 less than the initial cost. This difference can be qualified as a loss that occurred due to the influence of external circumstances.

Finishing this section, we emphasize once again that the Cost approach is not only costs, but also wear. It is the

$3 \mathrm{CU}$ - currency unit. possibility of adjusting the cost due to wear that makes the cost approach the same tool for measuring market value, which other approaches are (Sales Comparison or Income approaches). Note that it is the ability of known approaches to measure one market value of the same object in favor of the basic rule of the axiom of valuation theory, formulated, for example, in article [5], that the results of real estate valuation performed by different methods of all three approaches, independent of each other, should be approximately equal. It also notes that this rule should "work" at all stages of economic cycles, including periods of crisis falls and market rises.

\section{Calculation of Entrepreneurial Profit}

In the 14th edition of the textbook "Real estate appraisal" [9, page 574] it is noted that "entrepreneurial profit can be determined through market research, usually, through interviews with developers and other market participants about anticipated, acceptable, and actual levels of profit achieved in the market".

Russian experience also suggests that the profit of the entrepreneur can also be calculated by analyzing the recently implemented construction projects to determine the difference in sales prices and the amount of construction costs.

Both of these methods have their drawbacks. The expert survey method is characterized by subjectivity, and for analyzing market data it is sometimes difficult to find close analogues. It's obvious that it is not necessary to count on a high accuracy of calculating the profit of an entrepreneur using these methods.

Another, in our opinion, more rigorous and economically sound method of calculating the profit of the entrepreneur is possible.

To do this, we use the classic definition of the profit of the 
entrepreneur as the difference between the sale price of the property and the developer's labor and capital costs [9] and consider the formula for estimating the market value of a land plot by discounting cash flows as part of a typical development project to create a property:

$$
V_{L}=-C_{0}-\frac{C_{1}}{(1+Y)}-\ldots-\frac{C_{r}}{(1+Y)^{r}}+\frac{V_{r}}{(1+Y)^{r}} .
$$

Here $V_{L}$ - the market value of the land plot or rights to it; $r$ - the period for the creation of the property;

$C_{0}, C_{1}, \ldots, C_{r}-$ construction costs;

$V_{r}$ - the sale price of the property (reversion).

In accordance with the definition of the desired projected profit (incentive) $E P_{r}$ must be in the sale price of the property:

$$
V_{r}=\left(V_{L}+\sum_{i=0}^{r} C_{i}\right)+E P_{r}
$$

Where $\left(V_{L}+\sum_{i=0}^{r} C_{i}\right)$ - the investments, spent on the purchase of land and construction of the object (the return of capital).

Substitute (2) into (1):

$$
V_{L}=-C_{0}-\frac{C_{1}}{(1+Y)}-\ldots-\frac{C_{r}}{(1+Y)^{r}}+\frac{\left(V_{L}+\sum_{i=0}^{r} C_{i}\right)+E P_{r}}{(1+Y)^{r}}
$$

From here, you can highlight the desired profit of the entrepreneur:

$$
E P_{r}=V_{L}\left[(1+Y)^{r}-1\right]+\sum_{q=0}^{r-1} C_{q}\left[(1+Y)^{r-q}-1\right],
$$

Where $q-$ is discrete points in investment time.

Expression (3) is the mathematical model for calculating the projected profit of an entrepreneur (entrepreneurial incentive).

As noted above, the amount $\left(V_{L}+\sum_{i=0}^{r} C_{i}\right)$ is the total amount of investment in the creation of the property, starting with the acquisition of land rights at market value and ending with the last investment at time $r$.

In this expression, we specifically singled out the value of the land, thereby showing that investment in the purchase of land is involved in the formation of the profit of the entrepreneur along with other investment costs. Note that since the source of construction costs is all invested capital, the profit of an entrepreneur characterizes the total income of the project.

Thus, in order to calculate the entrepreneurial incentive in applying cost approach, it is necessary to analyze construction schedules similar to the object of evaluation, choose the appropriate yield rate, and substitute the found indicators into formula (3). Thus, we add the value of the projected profit to the costs of creating improvements and get the market value of the improvements like new, which we further consider for depreciation.

Note that the sum (3) from an economic point of view is the sum of the imputed costs. These costs, according to Joseph K. Eckert [see 10, p. 267], form the profit, which, together with the costs of construction work, forms the price of new facilities in a balanced market.

Formula (3) allows you to calculate the projected profit of the entrepreneur-developer in absolute terms. It characterizes the overall return on the project for the entire period, calculated in monetary units. This profit depends on the rate of return on capital, which characterizes the risk of investment in the project. The higher the risk, the higher the return on capital required by the developer and the higher the return he expects. It is easy to see that the projected profit of the entrepreneur, in addition to the rate of return on capital, also depends on the volume and schedule of investments, and the time of the project.

For clarity, the proposed method of calculation of the predicted profit of the entrepreneur (entrepreneurial incentive), consider a small example.

Example

The value of land rights $V_{L}=C U 100$.

The time of creation of the property is 3 years.

Investment Schedule:

$$
\mathrm{C}_{0}=\mathrm{CU} 100 ; \mathrm{C}_{1}=\mathrm{CU} 200 ; \mathrm{C}_{2}=\mathrm{CU} 300 ; \mathrm{C}_{3}=\mathrm{CU} 100 .
$$

Here $C_{0}=100 C U$ spent on the purchase of land, and the amount $\left(C_{1}+C_{2}+C_{3}\right)$ spent on construction: building materials and labor.

$$
\text { Yield rate } Y=10 \% \text {. }
$$

Proposed solution

Calculate according to the formula (3) entrepreneurial incentive:

$$
\begin{gathered}
E P_{r}=200\left[(1+0.1)^{3}-1\right]+200\left[(1+0.1)^{2}-1\right]+ \\
+300 \times 0.1=132.2(C U)
\end{gathered}
$$

Determine the total investment:

$$
V_{L}+C_{0}+C_{1}+C_{2}+C_{3}=800(C U)
$$

Therefore, the entrepreneurial incentive for the investor in absolute terms was $\mathrm{CU} 138.2$ or 17.3 percent of total investment.

Using this information, it is possible to calculate the value of the land improvements created and, in general, the value of selling the property, which will provide not only the return of the initial investment, but also the return on capital required by the investor.

Value of improvements:

$$
V_{B r}=C_{0}+C_{1}+C_{2}+C_{3}+E P_{r}=700+138.2=838.2(C U)
$$

If the property is not new, then this value should be used 
as a base for calculating all types of depreciation improvements (physical, functional and external). Note that there is no need to charge depreciation on the land plot, since the land is not a depreciable asset.

Value of sale (reversion):

$$
V_{r}=V_{B r}+V_{L}=838,2+100=938.2(C U) .
$$

\section{Comments for example}

From the point of general economic theory view, capital is obliged at any time and in any place, without stopping for a day, to bring income to its owner. During construction, investments (capital) are temporarily "frozen". Understanding this, as noted above, the owner of capital has the right to demand compensation for such "inaction", which he includes in the selling price of the finished property. This compensation is his entrepreneurial profit. When calculating it, it takes into account the time of "inaction" of capital, its volume and risks associated with the implementation of the project. The higher the risk, the higher the rate of return on capital Y. Obviously, it is more than bank interest. Note that when calculating profit, investments are taken into account not only in construction, but also in the purchase of a land plot, since they also temporarily do not work.

As noted in [9, 11-14], one of the drawbacks of the commonly used variant of the cost approach is the unrealistic assumption that improvements are created instantly. This disadvantage makes the cost approach somewhat artificial, which reduces the degree of confidence in its results. Our proposed method of calculation of entrepreneurial incentives, based on the calculation of imputed costs, eliminates this disadvantage, since it allows taking into account the time of creation of the property. Note that the developer begins to earn profits from the beginning of the project. This profit increases when he or she buy land, develop a project, enter into contracts, create improvements, etc. The mathematical model proposed for use allows one to predict this profit at any stage of project implementation.

The second disadvantage of the cost approach is the inability to take into account investment risks in the process of calculating the value of land improvement. The proposed method of the profit calculation allows us to eliminate this drawback, since in the formula (3) for calculating the entrepreneurial profit (incentive), the yield rate, which is proportional to the risks of investing in a project, is used as an argument.

\section{Conclusions}

1. An entrepreneur is a person who creates finances and manages a commercial or industrial organization, expecting to make a profit. Entrepreneurs involved in the creation of new real estate, often called the developer.

2. In the cost approach, the profit of an entrepreneur, which, together with costs, forms the value of land improvements, should be considered like a profit on all invested capital.

3. The need to add entrepreneurial profits to the costs of creating improvements is due to the fact that no reasonable developer will undertake to build and sell real estate without the ability to make a profit on their capital.

4. One should distinguish between the profit of the entrepreneur and the entrepreneurial incentive. Entrepreneurial incentive is the remuneration on which the entrepreneur expects, and the entrepreneur's profit is the real income that the entrepreneur will receive after the project is implemented by selling or leasing the created object. Entrepreneurial incentive can be defined as the predicted (expected) entrepreneurial profit.

5. The cost approach reflects the two sides of the market: supply and demand. The supply is reflected in the sum of costs and profits of the entrepreneur, and the demand - the accumulated depreciation of the object of evaluation.

6. If the appraiser, in the process of analyzing the market, concluded that it is expedient and possible to use the cost approach for the assessment, he or she should take the entrepreneurial incentive into account in his calculations.

7. The mathematical method of calculating the predicted profit of an entrepreneur, based on the calculation of imputed costs, eliminates two obvious drawbacks of the current version of the cost approach used in practice the inability to take into account the time factor and the invariance approach to investment risks.

\section{References}

[1] Korostelev Sergey P. "On the profits of an entrepreneur in the cost approach". Moscow University of Land Management, Russia, Moscow. URL http://www.labrate.ru/articles/korostelev_pp_and_costapproach-2009.pdf

[2] Yaskevich Evgeny E. Handbook of calculation data for assessment and consulting. Moscow Institute of Civil Engineering, Russia, Moscow: LLC "Scientific and Practical Center of Professional Appraisal", 2017.

[3] Kozyr Yuru V. Elements of valuation business. Moscow Institute of Physics and Technology. Russia, Moscow: Publishing House Option LLC, 2014.

[4] Fomenko Alexander N. "The method of updating the entrepreneur's previously determined profit in real estate valuation". Moscow University "Synergy", Moscow // Evaluation questions, №4, (2007)

[5] Ozero Evgeny S. Economic evaluation of civil rights objects. St.-Petersburg University of Technology. Department of Economics and Real Estate Management. Russia. St.Petersburg: Kopi-R Group LLC, 2012.

[6] Gribovsky Sergey V. Evaluation of income real estate: Textbook. Russia. St.-Petersburg: Peter, 2001.

[7] Gribovsky Sergey V. Property valuation: Textbook, Russia. Moscow: Maroseyka, 2017. 
[8] Korostelev Sergey P. "Other methodology and method of real estate appraisal in accordance with the interpretation of FSO7". Moscow University of Land Management. Russia. Moscow. URL http://www.ocenchik.ru/docsf/2049-metodocenki-nedvizhimosti-traktovkoy-fso7.html. 2014 year.

[9] The appraisal of real estate. - Fourteenth edition. Appraisal Institute • $200 \mathrm{~W}$. Madison • Suite $1500 \bullet$ Chicago, IL 60606 • 2013. (www.appraisalinstitute.org).

[10] Eckert Joseph K. Organization of assessment and taxation of non-movables. Volume I. Academy evaluation. Moscow: STAR INTER, 1997.

[11] Chakalyan Karine G. «Business valuation: the essence of the main approaches, their advantages and disadvantages» // Young Scientist. Russia. Moscow, (2016), No 28, 590-592.
[12] Vershinina Olga V. Theoretical bases of the expenses approach in the estimation of business cost Department of Finance and Banking, Moscow New University, Russia, Moscow, 2015.

[13] Friedman Jack, Ordway Nicolas. Analysis and evaluation of income-generating real estate. Russia, Moscow, Delo, 1998.

[14] Perevozchikov Alexander G. The General Theory of Credits and Its Applications to the Business Assessment: Study Guide. Russia, Moscow: Moscow Academician of the Academy of Natural Sciences. 2005.

[15] Federal Appraisal Standards "Property valuation (FSO 7)". APPROVED by order of the Ministry of Economic Development of Russia No. 611 dated September 25, 2014. 